Article

\title{
Epigenetic Modifiers Affect the Bioactive Compounds Secreted by an Endophyte of the Tropical Plant Piper longum
}

\author{
Fuad Ameen ${ }^{1, *}$, Abobakr Almansob ${ }^{1}$, Mona Al Tami ${ }^{2}$, Nouf Al-Enazi ${ }^{3}{ }^{1}$, Ahmed Al-Sabri $^{1}$ and Raha Orfali ${ }^{4}$ \\ 1 Department of Botany and Microbiology, College of Science, King Saud University, \\ Riyadh 11451, Saudi Arabia; aalmansob@ksu.edu.sa (A.A.); aalsbri@ksu.edu.sa (A.A.-S.) \\ 2 Department of Biology, College of Science, Qassim University, Qassim 51452, Saudi Arabia; tamie@qu.edu.sa \\ 3 Department of Biology, College of Science and Humanities in Al-Kharj, Prince Sattam Bin Abdulaziz \\ University, Al-kharj 11942, Saudi Arabia; n.alenazi@psau.edu.sa \\ 4 Department of Pharmacognosy, College of Pharmacy, King Saud University, P.O. Box 22452, \\ Riyadh 11495, Saudi Arabia; rorfali@ksu.edu.sa \\ * Correspondence: fuadameen@ksu.edu.sa; Tel.: +96-6114675862
}

check for updates

Citation: Ameen, F.; Almansob, A.; Al Tami, M.; Al-Enazi, N.; Al-Sabri, A.; Orfali, R. Epigenetic Modifiers Affect the Bioactive Compounds Secreted by an Endophyte of the Tropical Plant Piper longum. Molecules 2021, 26, 29. https://dx.doi.org/10.3390/molecules 26010029

Received: 24 November 2020 Accepted: 21 December 2020 Published: 23 December 2020

Publisher's Note: MDPI stays neutral with regard to jurisdictional claims in published maps and institutional affiliations.

Copyright: () 2020 by the authors. Licensee MDPI, Basel, Switzerland. This article is an open access article distributed under the terms and conditions of the Creative Commons Attribution (CC BY) license (https: / / creativecommons.org/ licenses/by/4.0/).

\begin{abstract}
Seven endophytic fungi were isolated from the tropical medicinal plant Piper longum L. After preliminary screening, Phomopsis heveicola was selected for the epigenetic activation treatments. The antibacterial, antifungal, and antioxidant potentials of crude extracts obtained from the treatments (with and without epigenetic modifiers) were analyzed in vitro. The extracts inhibited growth of the human pathogens Pseudomonas aeruginosa, Shigella sonnei, Streptococcus pyogenes, and Salmonella typhi, as well as the phytopathogens Puccinia recondita, Rhizoctonia solani, Phytophthora infestans, and Botrytis cinerea. Furthermore, DPPH-scavenging activity was higher in valproic acid treated extracts. Volatile chemicals with known biological activities (measured with GC-MS/MS), were released in the valproic acid treatment. The antimicrobial potentials of the extracts were confirmed using MRM/MS analysis. The experiments revealed a new promising endophytic fungus, $P$. heveicola, to be utilized in biological plant protection and in biomedical applications.
\end{abstract}

Keywords: endophytic fungi; Phomopsis; bioactivity; antagonistic; epigenetic modifier; small mass chemical

\section{Introduction}

The development of biomedicine and biocontrol agents offers valuable alternatives to the excessive use of chemical drugs and control agents. The search for biological agents has involved several organisms, including plants that have been utilized in traditional biomedicine [1]. Recently, not only plants but their endophytic microorganisms have been found to produce a great variety of biologically active metabolites [2]. Such metabolites might be used, for instance, as antibiotics, anticancer agents, or even against plant pathogens and insects [3,4]. Some of the metabolites are volatile organic compounds (VOCs) that exist as mixtures of simple hydrocarbons, heterocycles, aldehydes, ketones, alcohols, phenols, thioalcohols, thioesters and their derivatives, benzene derivatives, and cyclohexanes [3]. Several VOCs produced by endophytic fungi have been shown to promote plant growth and vigor, and control plant pathogens [4].

Endophytic microorganisms that cooperate with their host plants produce metabolites that are transferred between the plant and the endophytes. Many endophytic species have been identified from different plant species and from different organs. Fusarium tricinctum has been isolated from the roots of Panax notoginseng; Aspergillus oryzae from Raphanus sativus; Pseudomonas stutzeri from the rhizosphere and endosphere of Oryza sativa; and Penicillium canescens from the roots, stems, and leaves of Cajanus cajan, to mention some examples [2]. The metabolite cocktails are unique and depend on several factors that are still largely unknown [5]. Even less is known about the mechanisms behind metabolite 
production [6]. It is known that many metabolites are silent (i.e., their genes are not expressed under laboratory conditions) [7]) but the development of epigenetics has allowed for great discoveries in this field [8]. Metabolites have been observed to be secreted when the organisms were treated with specific low-molecular-mass epigenetic modifiers $[9,10]$. The recently emerged research field of epigenetics has also shown the importance of epigenetic activation in microorganisms secreting metabolites [11-13]. The research has offered possibilities for novel biomedical applications. For example, the production of compounds against malaria and methicillin-resistant Staphylococcus aureus was enhanced when epigenetic modifiers were employed to activate the genes of the marine fungus Leucostoma persooniimarine, an endophyte of mangroves [14]. Similarly, epigenetic activation enhanced production of anti-inflammatory, antidiabetic, and antimicrobial compounds in several fungi [15-19]. However, their production for commercial use needs still to be developed.

It has been suggested that every known fungus has the potential to produce antimicrobial compounds when treated with the right epigenetic modifiers [7]. However, further studies are needed to discover more species and novel antimicrobial substances, as concluded in a 2019 review by [12]. In their review, they showed that Aspergillus and Fusarium were the model genera in epigenetic studies for secondary metabolite production. The organisms were selected from similar habitats (mostly marine ecosystems). Consequently, in the present study we introduced a new habitat—a humid, tropical agricultural site-and a new plant species, Piper longum L.

The goal of the present study was to develop antimicrobial agents by taking advantage of the epigenetic activation of endophytic fungi isolated from P. longum, which is widely used in traditional Indian medicine to treat diseases such as tuberculosis, respiratory tract infections, dementia, epilepsy, and asthma [20]. Piper longum is known to release volatile metabolites such as piperine and piperidine [21]. However, production needs to be made more efficient for commercial use. Therefore, we isolated and identified endophytic fungi from $P$. longum and carried out experiments with two common epigenetic modifiers. We analyzed the crude extracts of $P$. longum grown in different culturing media for the fungal metabolites produced, as well as for its antimicrobial, antifungal, and antioxidant activities.

\section{Results and Discussion}

The endophytic fungus selected after antimicrobial screening showed $100 \%$ homology with $P$. heveicola, based on internal transcribed spacer (ITS) rRNA gene sequencing. The sequence was submitted to GenBank, NCBI, with the accession number MN857741.

\section{Bioactivity Analysis}

The crude extracts of the controls without epigenetic modifiers had weak antibacterial activity against $P$. aeruginosa, $S$. sonnei, and S. pyogenes, and weak antifungal activity against $R$. solani and $P$. infestans. The rest of the pathogens were not inhibited by the crude extracts.

In the two-way ANOVA of each pathogenic species, there were significant interactions between the epigenetic modifiers and their concentrations, indicating that the effects of the modifiers depended on their concentrations. The antimicrobial activities of the crude extracts of $P$. heveicola varied significantly depending on the epigenetic modifier and the concentration at which it was used. For a detailed inspection, $t$-tests were carried out to compare each concentration of epigenetic modifier separately to the respective positive control within the pathogenic species. In some cases, the positive control had more antimicrobial activity than the tested P. heveicola extract. Only antimicrobial effects higher than the positive controls were tested and reported.

In general, the valproic acid treatment resulted in higher antibacterial and antifungal activities than the 5-azacytidine treatment. In the $t$-tests, 5 -azacytidine had no significant effect on either antimicrobial or antifungal activity compared to the positive controls.

Shown using a $t$-test, valproic acid had a significantly higher antibacterial efficiency than the positive controls in some cases (Figure 1). The lowest concentration valproic 
acid treatment $(0.5 \mu \mathrm{g} / \mathrm{mL})$ presented a $37 \%$ higher inhibition zone against $S$. typhi than the positive control. Valproic acid at a concentration of $5 \mu \mathrm{g} / \mathrm{mL}$ had $20 \%, 25 \%$, and $17 \%$ higher inhibition zones against the bacteria P. aeruginosa, S. sonnei, and S. pyogenes, respectively, compared to the positive controls. The highest concentration of valproic acid tested $(50 \mu \mathrm{g} / \mathrm{mL})$ had a $23 \%$ higher inhibition zone against S. pyogenes than the positive control.

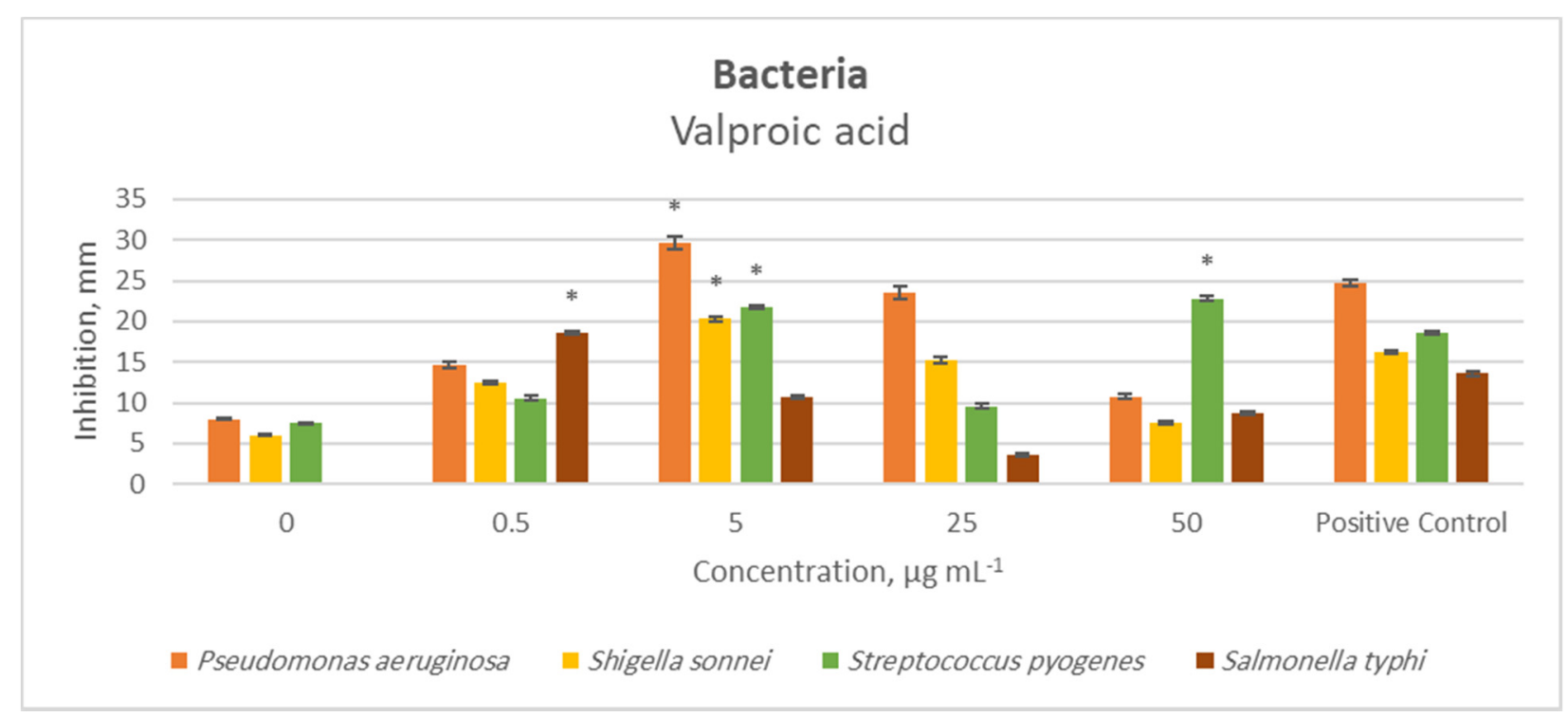

(A)

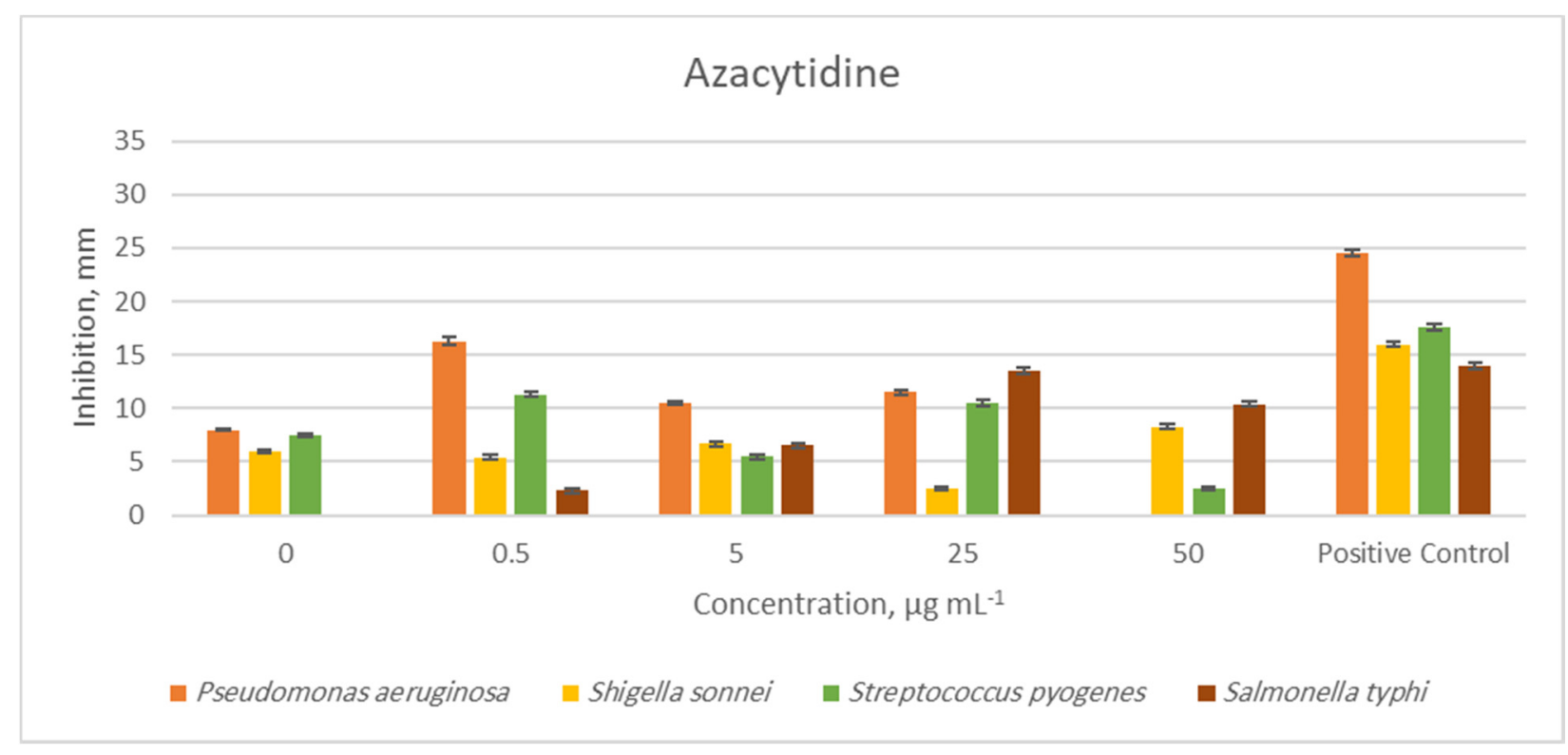

(B)

Figure 1. Antibacterial activity (zone of inhibition, mean, and SD error bars, $n=3$ ) of the crude extract of the endophytic fungus P. heveicola cultured with different concentrations of the epigenetic modifiers valproic acid (A) and 5-azacytidine (B), where $0 \mu \mathrm{g} / \mathrm{mL}$ refers to the control treatment. The positive control contains ampicillin + tetracycline. ${ }^{*}$ indicates significant difference $(t$-test, $p<0.05)$ from the positive control.

In the $t$-tests of antifungal activity, 5-azacytidine had no increasing effects on the inhibition zones when compared to the positive controls (Figure 2). The lowest concentration valproic acid treatment $(0.5 \mu \mathrm{g} / \mathrm{mL})$ caused a $21 \%$ higher inhibition zone against $P$. recondite than the positive control. Valproic acid at $5 \mu \mathrm{g} / \mathrm{mL}$ resulted in $8 \%, 13 \%$, and $12 \%$ higher 
inhibition zones against $R$. solani, P. infestans, and B. cineria, respectively, compared to the positive controls. Valproic acid at $25 \mu \mathrm{g} / \mathrm{mL}$ resulted in a $21 \%$ higher inhibition zone against $P$. infestans than the positive controls. The highest concentration of valproic acid did not have a significant increasing effect on antifungal activity.

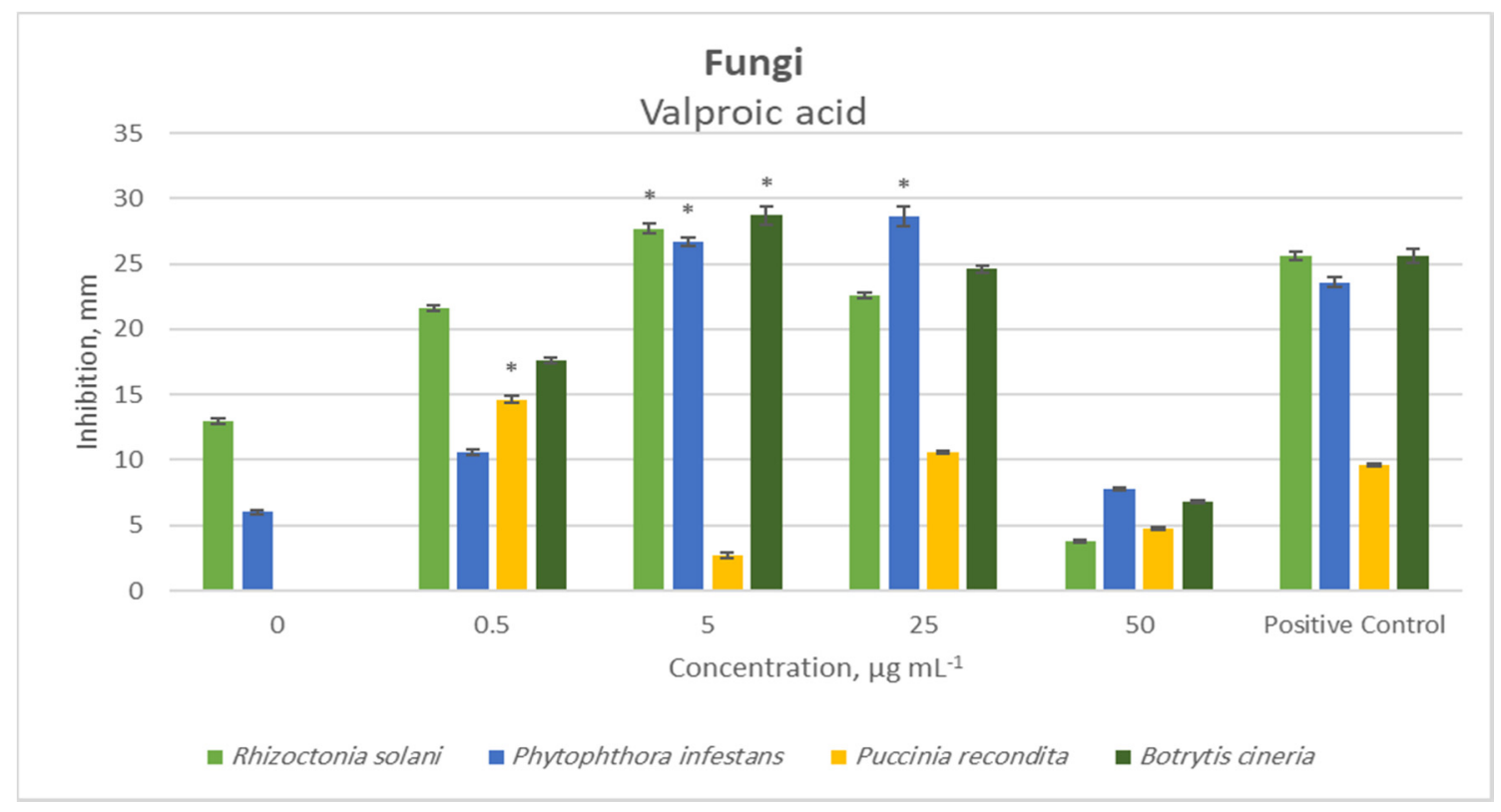

(A)

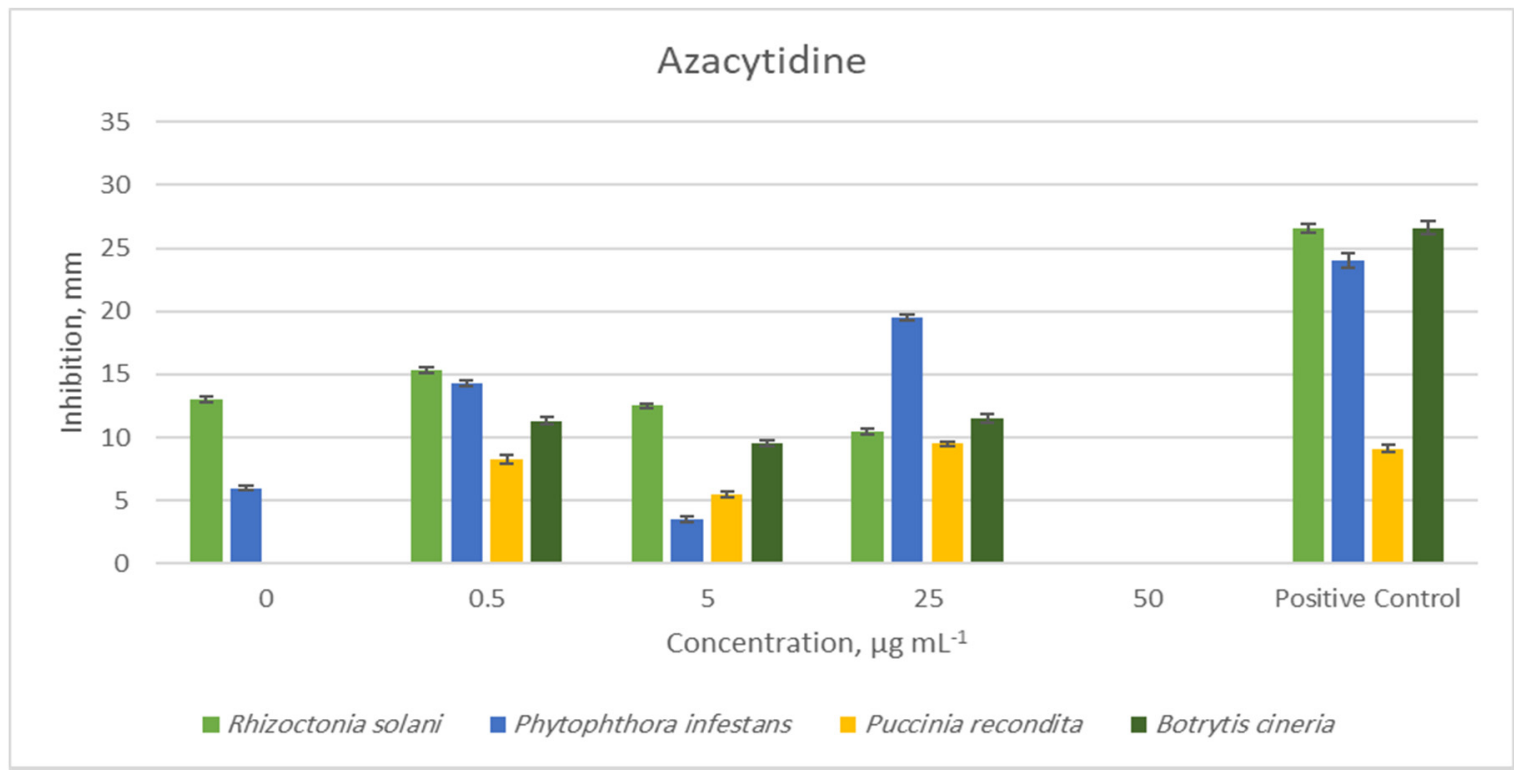

(B)

Figure 2. Antifungal activity (zone of inhibition, mean, and SD error bars, $n=3$ ) of the crude extract of the endophytic fungus $P$. heveicola cultured with different concentrations of the epigenetic modifiers valproic acid (A) and 5-azacytidine (B), where $0 \mu \mathrm{g} / \mathrm{mL}$ refers to the control treatment. The positive control contains gentamycin + fluconazole. ${ }^{*}$ indicates significant difference $(t$-test, $p<0.05)$ from the positive control.

The antioxidant potential is a useful measure to assess the biologically active metabolites. Antioxidants scavenge free radicals minimizing their adverse effects. In this study, we assessed the antioxidant potential with a common technique DPPH-scavenging activity [22]., which increased along with the epigenetic modifier concentration used (Table 1) 
similar to positive control rosmarinic acid. The valproic acid treatment increased DPPH activity more than the 5-azacytidine treatment. At their lowest concentrations, valproic acid had a low DPPH radical-scavenging activity (3\%), while 5-azacytidine had a comparatively high $(21 \%)$ scavenging activity. However, at the highest concentrations, the respective values were $71 \%$ and $60 \%$.

Table 1. Antioxidant potential assessed as DPPH radical scavenging activity (percentage of control with no epigenetic modifier addition, mean $\pm \mathrm{SD}, n=3$ ) of the crude extract of $P$. heveicola cultured in medium with different concentrations of two epigenetic modifiers. In addition, included positive control roamarinic acid and negative control glucose.

\begin{tabular}{|c|c|c|c|c|}
\hline \multicolumn{5}{|c|}{ Epigenetic Modifier } \\
\hline $\begin{array}{c}\text { Concentration, } \\
\mu \mathrm{g} \mathrm{mL}^{-1}\end{array}$ & Positive Control & $\begin{array}{c}\text { Negative } \\
\text { Control }\end{array}$ & Valproic Acid & Azacytidine \\
\hline 0.5 & $23 \pm 1$ & $1 \pm 2$ & $3 \pm 2$ & $21 \pm 5$ \\
\hline 5 & $42 \pm 1$ & $1.4 \pm 2$ & $28 \pm 9$ & $51 \pm 8$ \\
\hline 25 & $73 \pm 3$ & $1 \pm 2$ & $68 \pm 5$ & $58 \pm 7$ \\
\hline 50 & $83 \pm 1$ & $1.3 \pm 2$ & $71 \pm 8$ & $60 \pm 6$ \\
\hline
\end{tabular}

The presence of the antibiotic compound phenazine-1-carboxylic acid was observed with a multiple reaction monitoring mass spectrometry (MRM-MS) system. The standard peak was detected in the retention time of $1.10 \mathrm{~min}$ (Figure 3A), which was similar to the valproic acid treatment (1.05 $\mathrm{min}$ ) (Figure 3B). No other treatments were detected at the peak. The extract from the valproic acid treatment resulted in a mass of $181 \mathrm{kDa}$ (positive mode of ionization), while the mass of phenazine-1-carboxylic acid was $180 \mathrm{kDa}$ (Figure 3C).

MRM-MS analysis confirmed that the endophytic fungus P. heveicola produced antibiotics after valproic acid treatment. Phenazine and its derivatives are heterocyclic nitrogen compounds that have been reported to have activity against Gaeumannomyces sp., Fusarium sp., Pythium sp., Rhizoctonia solani, Gibberella spp., Drechslera graminea, and Alternaria spp. [23]. These compounds have mainly been detected from a Pseudomonas sp. [24] and a Streptomyces sp. [25], whereas endophytic fungi-derived phenazine derivatives are rarely reported. An endophytic fungus, Nigrospora oryzae, isolated from Coccinia grandis has been reported to produce phenazine-l-carboxamide [26]. Our study can add the endophytic $P$. heveicola isolated from P. longum.

The crude extract of the control treatment and the extracts of the 5-azacytidine treatments contained no valuable chemicals (data not shown). However, the valproic acid treatments resulted in several chemicals in the crude extracts, depending on the valproic acid concentration used. The lowest concentration of valproic acid tested $(0.5 \mu \mathrm{g} / \mathrm{mL})$ contained cyclopropane $\left(\mathrm{C}_{3} \mathrm{H}_{6}\right)$ with $4.9 \%$ relative abundance (Figure $\left.4 \mathrm{~A}\right)$. The concentration of $5 \mu \mathrm{g} / \mathrm{mL}$ led to oxathiazole 2 thione $\left(\mathrm{C}_{2} \mathrm{H}_{3} \mathrm{NOS}_{2}\right)$ and pyrrolo [1,2-a]pyrazine1,4-dione,hexahydro-3,2-methyl $\left(\mathrm{C}_{11} \mathrm{H}_{18} \mathrm{~N}_{2} \mathrm{O}_{2}\right)$ with relative abundances of $3.8 \%$ and $24 \%$, respectively (Figure $4 \mathrm{~B})$. Cyclopentadecanolide $\left(\mathrm{C}_{15} \mathrm{H}_{28} \mathrm{O}_{2}\right)$; $\mathrm{N}$-allyldecylamine $\left(\mathrm{C}_{13} \mathrm{H}_{27} \mathrm{~N}\right)$; oxazole, 4-ethyl-4,5-dihydro-2-(2-hydroxyphenyl)- $\left(\mathrm{C}_{11} \mathrm{H}_{13} \mathrm{NO}_{2}\right)$; and benzyl ethanoate $\left(\mathrm{C}_{9} \mathrm{H}_{10} \mathrm{O}_{2}\right)$ were present in the extracts of $25 \mu \mathrm{g} / \mathrm{mL}$ of valproic acid treatment with relative abundances of $14 \%, 38 \%, 55 \%$, and $48 \%$, respectively (Figure $4 \mathrm{C}$ ). Diphenan $\left(\mathrm{C}_{14} \mathrm{H}_{13} \mathrm{NO}_{2}\right)$ and methyl 2,3-anhydro-4,6-O-benzylidenehexopyranoside $\left(\mathrm{C}_{14} \mathrm{H}_{16} \mathrm{O}_{5}\right)$ were detected in the crude extract of $50 \mu \mathrm{g} / \mathrm{mL}$ concentration with $24 \%$ and $37 \%$ relative abundances, respectively (Figure $4 \mathrm{D}$ ) (Table 2). 


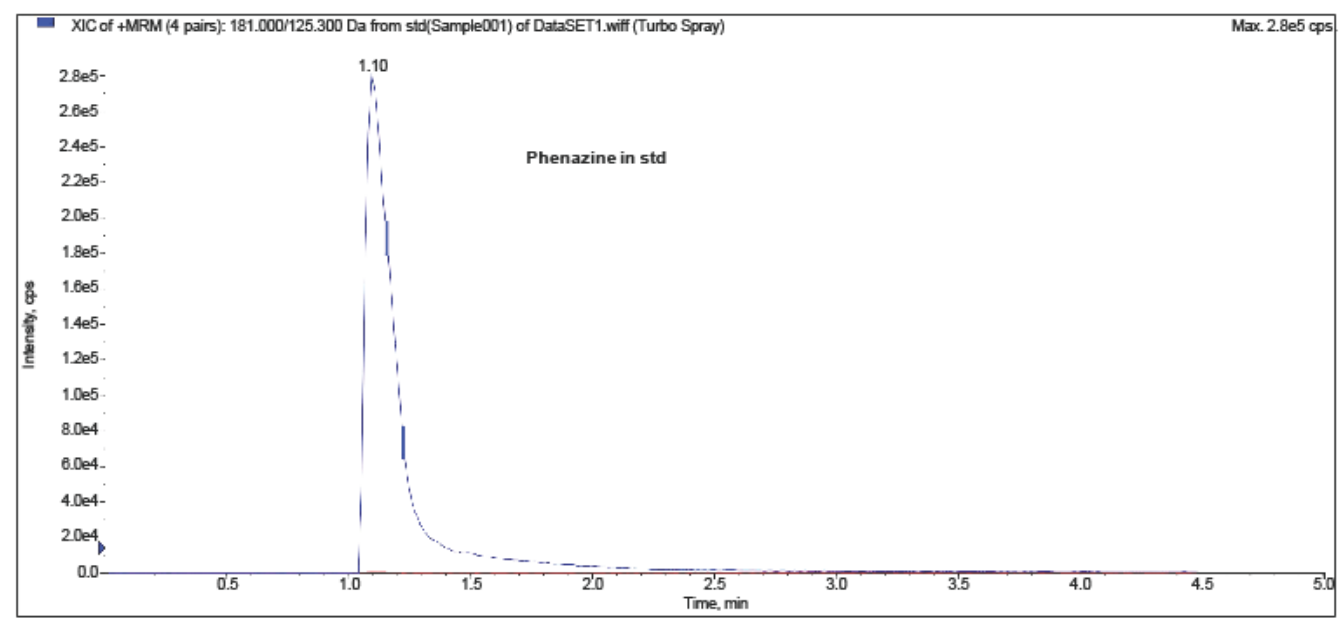

(A)

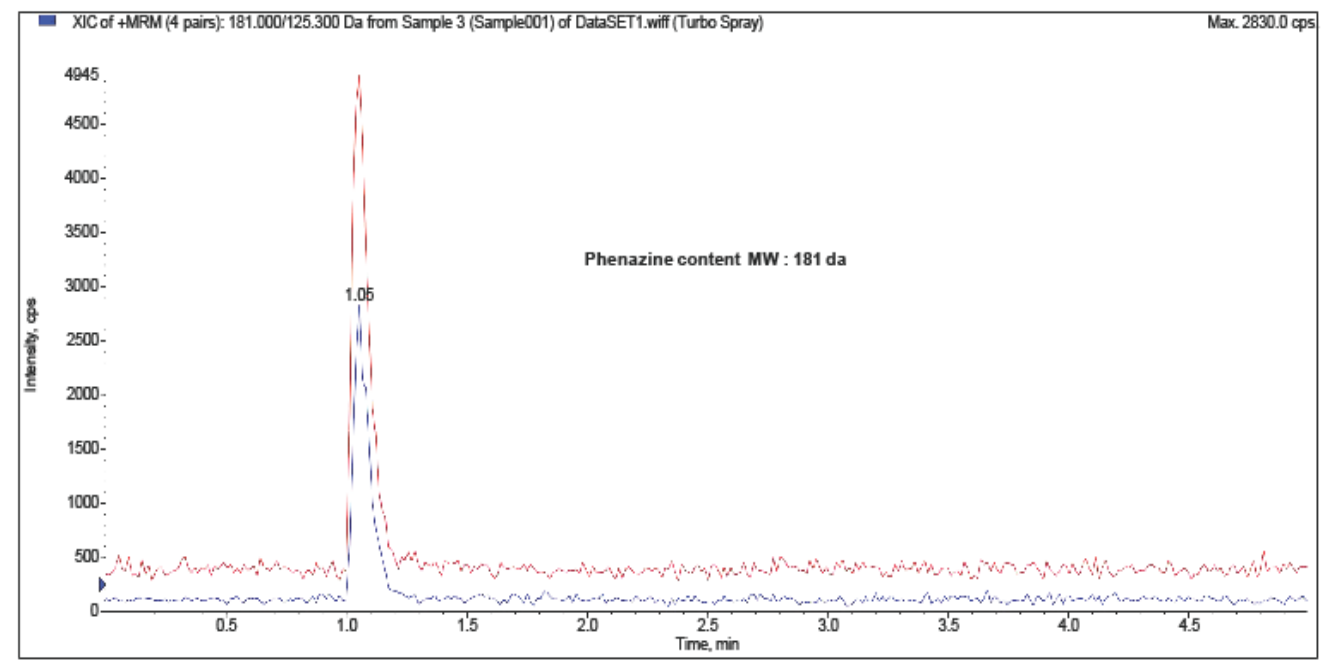

(B)

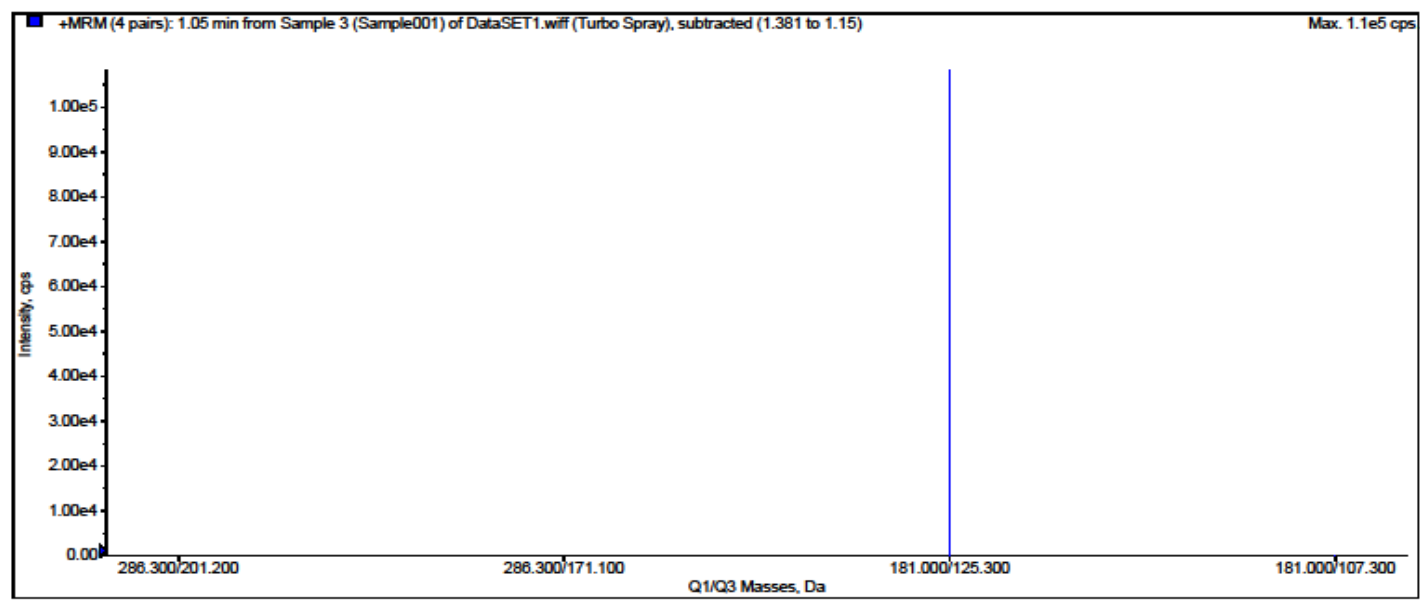

(C)

Figure 3. MRM-MS of phenazine-1-carboxylic acid $\left(\mathrm{C}_{12} \mathrm{H}_{8} \mathrm{~N}\right)$. (A) Standard peak was detected in the retention time of 1.10 min at a wavelength of $248 \mathrm{~nm}$. (B) The endophytic fungal valproic acid treated extract also peaked at the retention time of $1.05 \mathrm{~min}$. (C) MRM-MS detected that the extract of endophytic fungus contained a mass at $181 \mathrm{kDa}$ (positive mode of ionization). The mass of phenazine-1-carboxylic acid is $180 \mathrm{kDa}$. 


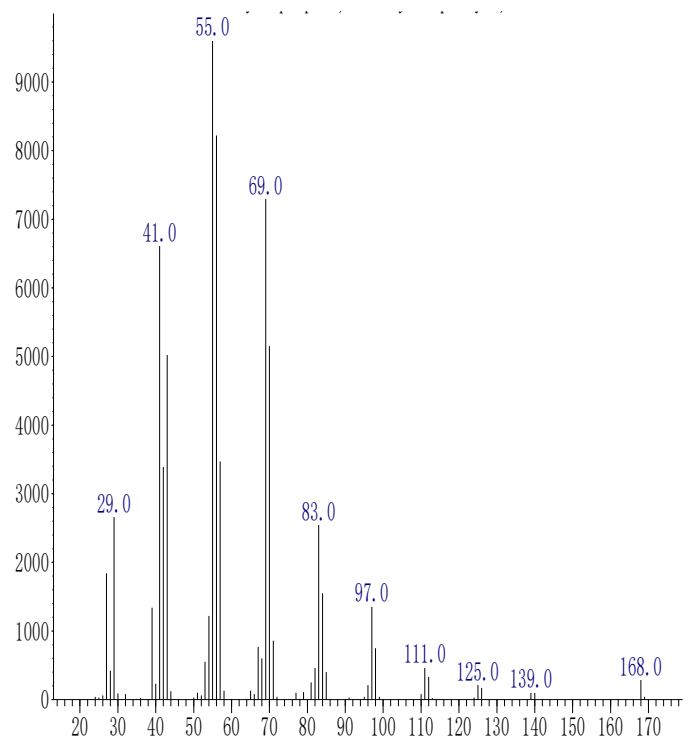

(A)

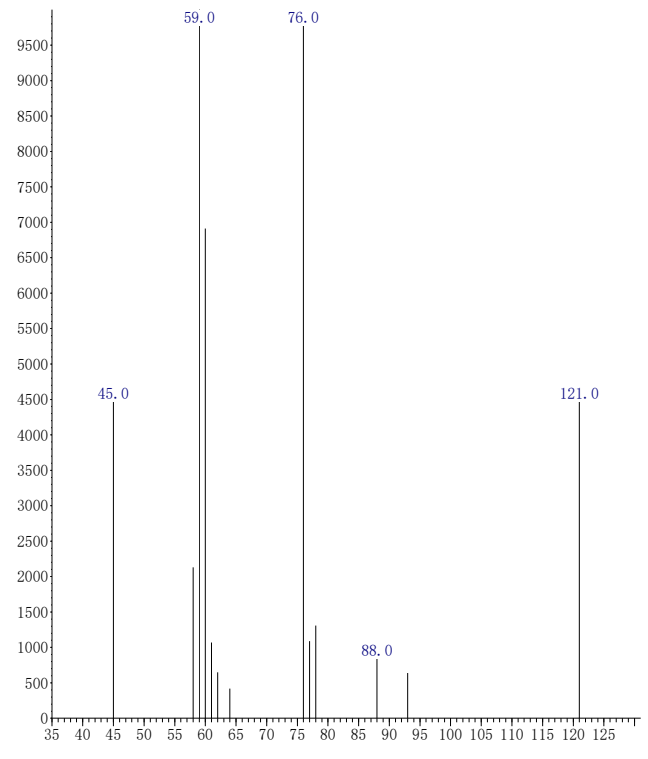

(B1)

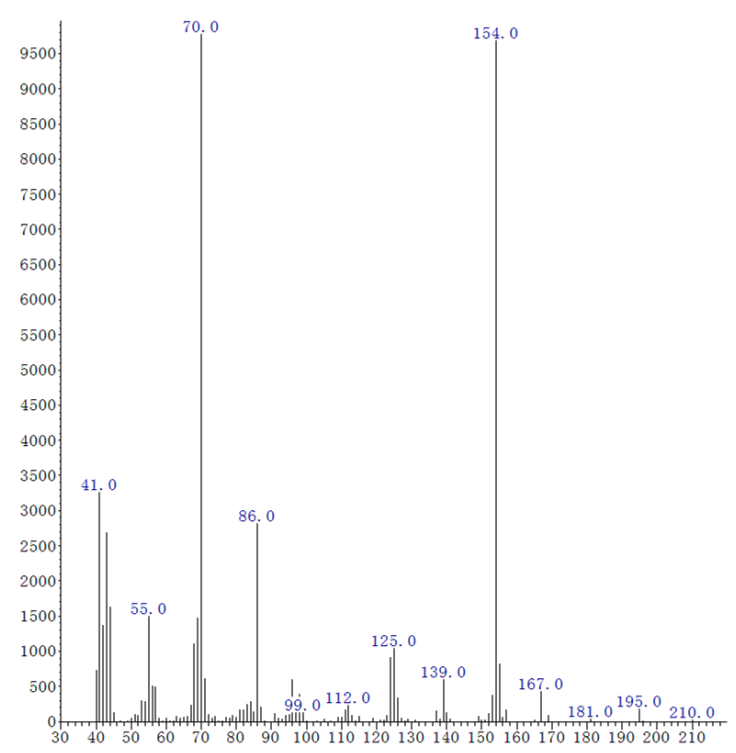

(B2)

Figure 4. Cont. 

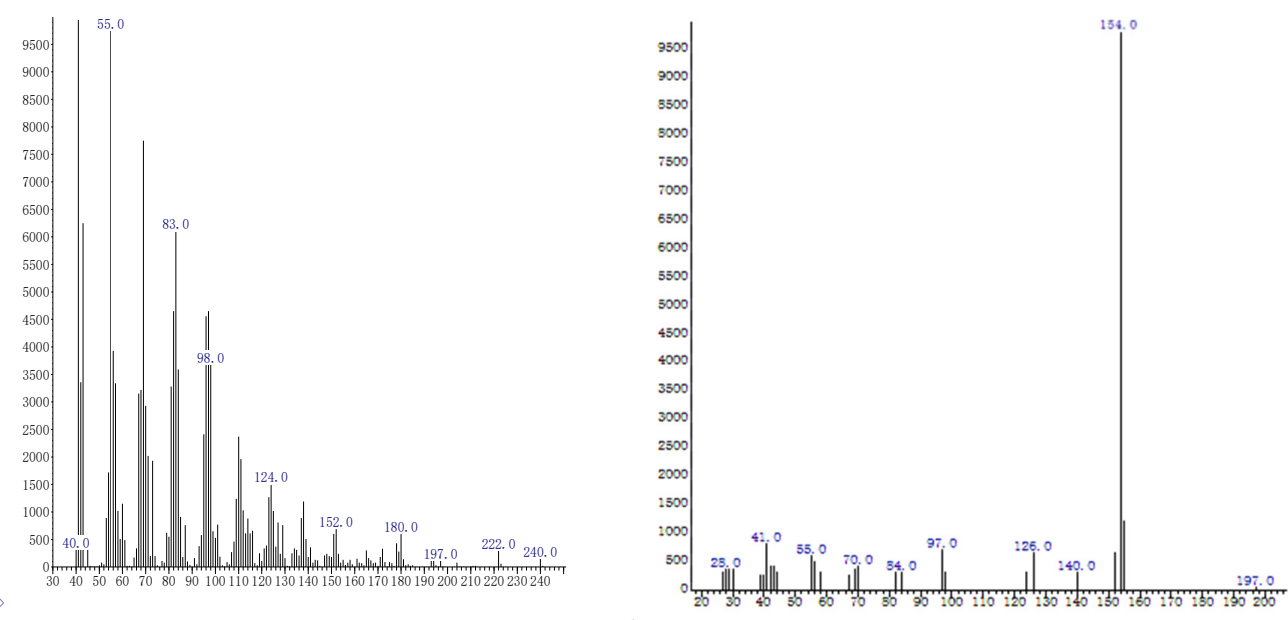

(C1)

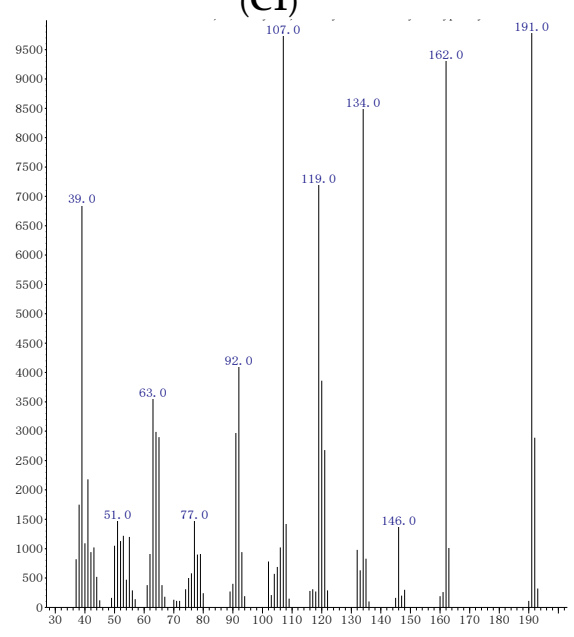

(C2)

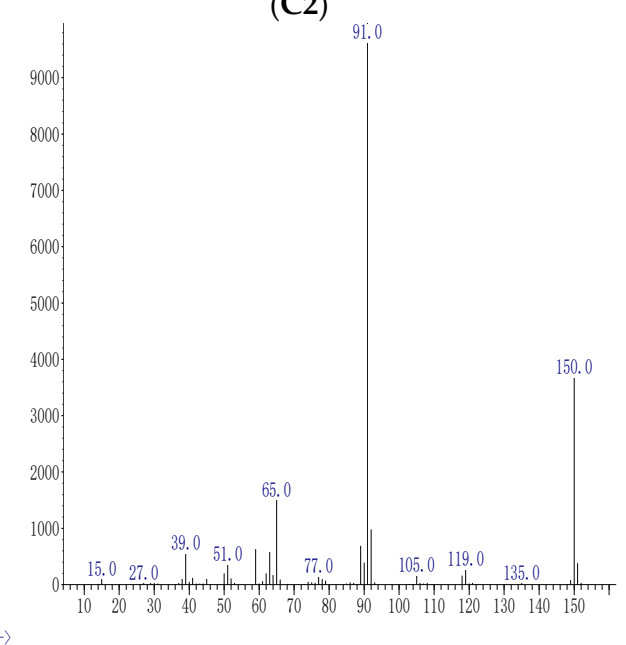

(C3)

(C4)

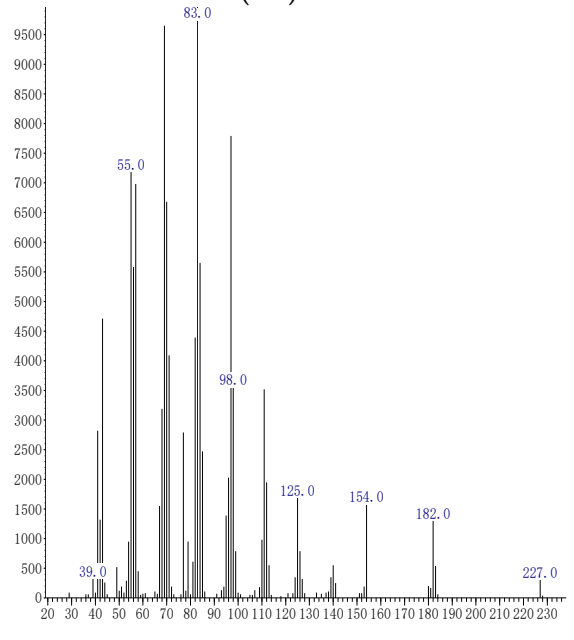

(D1)

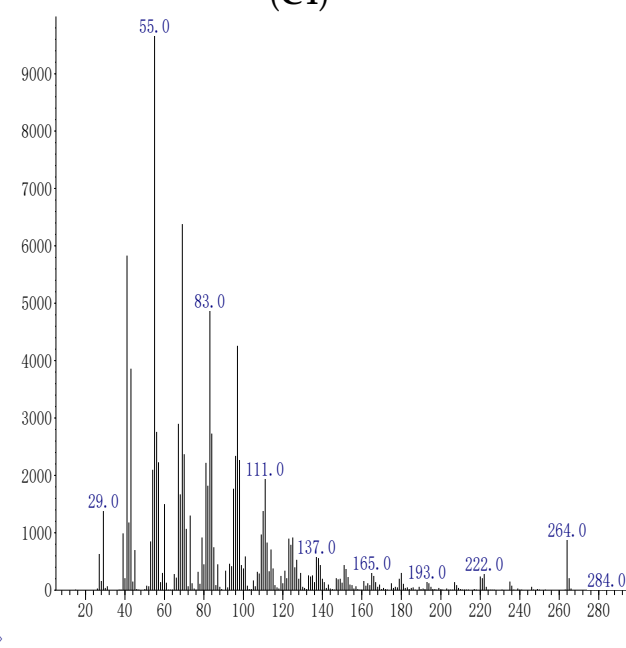

(D2)

Figure 4. GC-MS/MS mass spectra of the crude extract prepared from the medium of the endophytic fungus $P$. heveicola cultured with valproic acid as an epigenetic modifier at different concentrations. (A) $0.5 \mu \mathrm{g} / \mathrm{mL}$ cyclopropane. (B) $5 \mu \mathrm{g} / \mathrm{mL}$ : Oxathiazole 2 thione (B1) and pyrrolo[-1,2-a] pyrazine-1,4-dione,hexahydro-3,2-methyl (B2). (C): $25 \mu \mathrm{g} / \mathrm{mL}$ cyclopentadecanone (C1); oxazole (C2), 4-ethyl 4,5-dihydro 2,2-hydroxy phenyl (C3); and benzene acetic acid (C4). (D) $50 \mu \mathrm{gg} / \mathrm{mL}$ chloroacetic acid (D1) and cis-vaccenic acid (D2). 


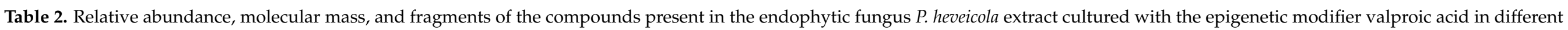
concentrations $\left(\mu \mathrm{g} \mathrm{mL}^{-1}\right)$ as identified using GCMS/MS analysis.

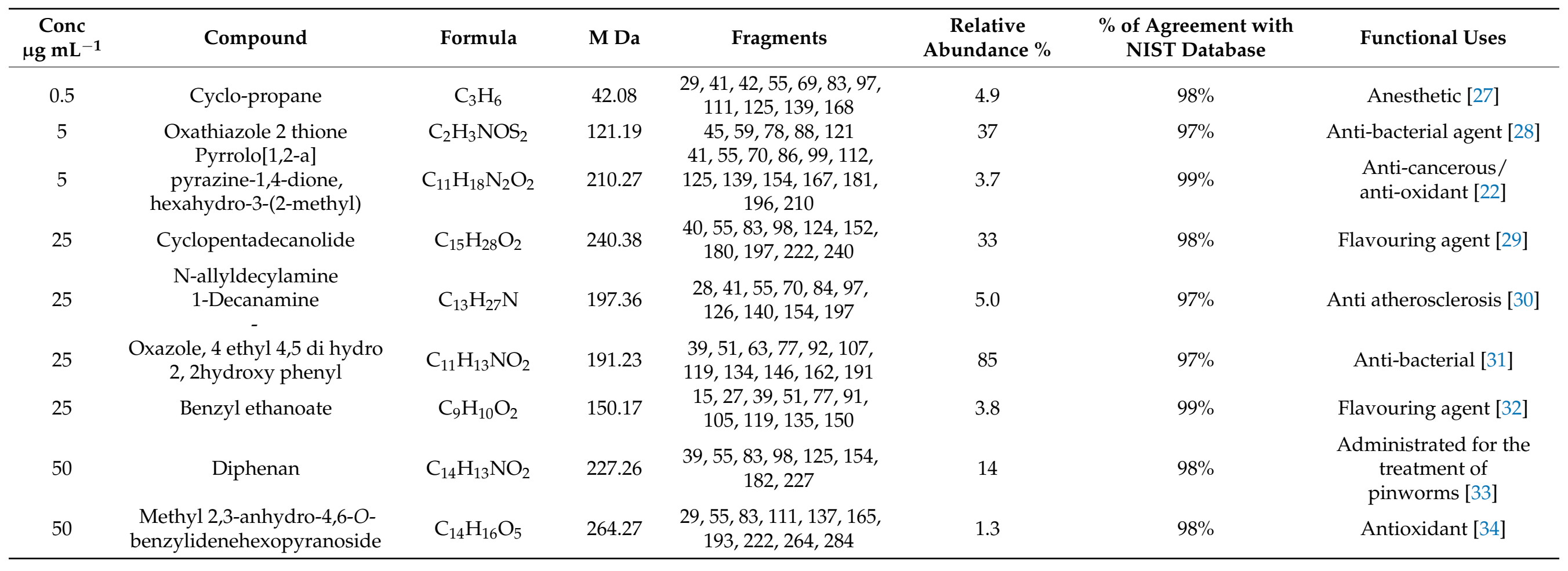


All the biological activities studied depended on the epigenetic modifier and concentration used. We interpreted that 5-azacytidine did not act as an effective epigenetic modifier, in contrast to valproic acid that was an effective epigenetic modifier of endophytic $P$. heveicola. We showed that the histone deacetylase inhibitor (valproic acid) had the ability to activate silent pathways of the endophytic fungus $P$. heveicola, whose metabolites had remarkable activity against both human and plant pathogens. The metabolites inhibited the growth of four clinical human pathogenic bacteria, namely P. aeruginosa, S. sonnei, S. pyogenes, and S. typhi. The metabolites also inhibited four plant pathogenic fungi, namely $R$. solani, $P$. recondita, $P$. infestans, and B. cineria. The antioxidant assays gave somewhat different results because both epigenetic modifiers seemed to induce antioxidant activity of $P$. heveicola medium extracts. However, antioxidant potential increased remarkably along with the epigenetic modifier concentration only in valproic acid treatments. Therefore, we concluded that valproic acid was a more effective epigenetic modifier than 5-azacytidine.

Our experiment with different concentrations of epigenetic modifiers revealed great variation in biological activities depending on the concentration of the epigenetic modifier used. In some cases, the positive controls had more antimicrobial activity than the treated $P$. heveicola extracts, indicating that the antibiotics and fungicides were more effective than the biological agents. These great differences between the pathogenic species and the effective concentrations of valproic acid call for further detailed studies. However, in all cases, valproic acid showed its ability to act as an effective epigenetic modifier for endophytic $P$. heveicola and should be studied further.

Both epigenetic modifiers we used have previously been observed to induce metabolite secretion in certain organisms to help the overexpression of specific genes [18]. Endophytic fungi Leucostoma persoonii, Alternaria sp., and Pestalotiopsis acacia have been reported to be induced by 5-azacytidine [14]. Valproic acid was reported as an efficient epigenetic modifier of endophytic Nigrospora sphaerica [35]. Valproic acid was also observed to induce the endophytic fungus Aspergillus fumigatus [36]. In that study, $5 \mu \mathrm{g} / \mathrm{mL}$ of valproic acid was the most effective concentration, resulting in a tenfold increase in the production of bioactive compounds. In our study, the same concentration also appeared to be the most efficient. However, we observed differences between the pathogens and, therefore, we suggested that different concentrations induced production of different chemicals. One possibility to improve metabolite secretion might be to combine different epigenetic modifiers. For instance, [37] found that using valproic acid in combination with procaine induced metabolite production of a Xylariaceae species.

Biological properties of chemical compounds-such as Oxathiazole 2 thione; pyrrolo [1,2-a]pyrazine-1,4-dione, hexahydro-3-(2-methyl); cyclopentadecanolide, $\mathrm{N}$ - allyldecylamine 1-decanamine; oxazole, 4-ethyl-4,5-dihydro-2-(2-hydroxyphenyl)-; benzyl ethanoate; diphenan; and methyl 2,3-anhydro-4,6-O-benzylidenehexopyranoside)have previously been reported to have high free-radical-scavenging, antifungal, and antibacterial activity in the PubChem database (PubChem is a registered trademark of the U.S National Library of Medicine). For the first time, the compounds were observed to be released by $P$. heveicola isolated as an endophyte of $P$. longum.

$P$. longum has been studied for its antimicrobial metabolites before. The endophytic fungus Periconia sp. was reported to produce piperine (5-(3,4-methylenedioxyphenyl)1-piperidinopent-2,4-dien-1-one) that displayed antibacterial activity against Mycobacterium tuberculosis and M. smegmatis [38]. More often than P. longum, another Piper species called P. nigrum and its endophytes have been studied for their piperine release, as reviewed recently by [39]. Reference [40] reported that the endophytic fungus Colletotrichum gloeosporioides from $P$. nigrum also released plant specific metabolite piperine.

We isolated and identified P. heveicola as an endophyte of $P$. longum. Many different Phompsis species have been reported as phytopathogens and sources of potential biological control agents [40]. P. cassie was reported as an endophytic fungus that released bioactive compounds in the plant Cassia spectabilis [41]. The endophytic fungus of rice P. liquidambari had a role in nitrogen transformations by improving the nutrient uptake of rice [41]. 
Previous reports on P. heveicola are scarce. P. heveicola was reported as an endophyte of mangroves in India [42]. The species was also reported as a coffee pathogen in China [43]. However, we did not find reports regarding the biologically active metabolites of P. heveicola.

\section{Materials and Methods}

\subsection{Endophytic Fungi Isolation from Piper longum L.}

Twenty Piper longum plants were collected from the Rama Farm, Al-Qassim, Saudi Arabia $\left(26^{\circ} 5^{\prime} 38.7168^{\prime \prime} \mathrm{N}\right.$ and $\left.43^{\circ} 58^{\prime} 24.4344^{\prime \prime} \mathrm{E}\right)$ and stored at $4^{\circ} \mathrm{C}$. For surface sterilization, the plant stems and roots were soaked successively in 70\% ethanol (1 min), $3 \%$ sodium hypochlorite ( $3 \mathrm{~min}$ ), and 70\% ethanol (30 s) as described by [44]. Finally, the ethanol was removed using sterile distilled water. The disinfection efficiency was checked by adding the final rinse onto Petri plates containing potato dextrose agar (PDA) (200 g potato extract, $20 \mathrm{~g}$ dextrose, $15 \mathrm{~g}$ agar, $\mathrm{pH}$ 6.5) and Manihot dextrose agar (MDA) (200 g cassava, $20 \mathrm{~g}$ dextrose, $15 \mathrm{~g}$ agar, $\mathrm{pH}$ 6.5). The extracts of potato and cassava were prepared by using $200 \mathrm{~g}$ of the plants cut into small pieces and boiled. Dextrose was added to the infusion and the $\mathrm{pH}$ was adjusted using $1 \mathrm{M} \mathrm{HCl}$.

The stems of the plants were cut into $4-6 \mathrm{~mm}$ pieces and placed onto Petri dishes containing PDA or MDA supplemented with both tetracycline $(50 \mu \mathrm{g} / \mathrm{mL})$ and streptomycin $(50 \mu \mathrm{g} / \mathrm{mL})$ to inhibit bacterial growth. The plates were incubated at $28^{\circ} \mathrm{C}$, and when the fungal mycelium appeared after 5-6 days, the fungi were transferred onto new PDA and MDA plates and incubated again for seven days. After incubation, the plates were stored at $4{ }^{\circ} \mathrm{C}$ for further study. Primary identification of the isolates was carried out using the Lactophenol Cotton Blue Staining method [45] and scanning electron microscopy as described by [46]. A primary screening of seven morphologically different fungi was carried out using an antibacterial assay (explained below). The species with antibacterial activity were chosen for further investigation.

\subsection{Molecular Identification of the Endophytic Fungi}

Potato dextrose broth (PDB) $(2 \mu \mathrm{L})$ was added into endophytic fungal culture tubes and vortexed to collect spores $\left(1 \times 10^{9}\right.$ spores $\left./ \mathrm{mL}\right)$. Then, the PDB and spores were poured into $100 \mathrm{~mL}$ flasks containing only PDB and incubated on a rotary shaker at $150 \mathrm{rpm}$ for three days at room temperature. After that, the mycelium was filtered and frozen at $-80^{\circ} \mathrm{C}$ for $30 \mathrm{~min}$ and lyophilized. The mycelium was ground with liquid nitrogen using a sterile mortar to obtain mycelium powder. DNA was extracted using a DNeasy fungal mini kit. The ITS regions of the DNA (ITS1: 5'-TCCGTAGGTGAACCTGCGG-3' and ITS4: $5^{\prime}$-TCCTCCGCTTATTGATATGC- $3^{\prime}$ ) were amplified by PCR using the following thermal cycles: initial denaturation at $95{ }^{\circ} \mathrm{C}$ for $5 \mathrm{~min}$, denaturation with 35 cycles at $94{ }^{\circ} \mathrm{C}$ for $1 \mathrm{~min}$, annealing at $55^{\circ} \mathrm{C}$ for $30 \mathrm{~s}$, extension at $72{ }^{\circ} \mathrm{C}$ for $2 \mathrm{~min}$, and a final extension at $72{ }^{\circ} \mathrm{C}$ for $10 \mathrm{~min}$. Sequencing was carried out using a BigDye Terminator sequencing kit (Applied Biosystems, Foster City, CA, USA). The alignment and phylogeny reconstructions were performed with the 'build' function of ETE3 v3.1.1(EMBL, Heidelberg, Germany) [47] as implemented on the Genome Net (https://www.genome.jp/tools/ete/).

\subsection{Epigenetic Modifier Experiments}

Two commonly used and efficient epigenetic modifiers, valproic acid and 5-azacytidine, were tested at four concentrations $(0.5,5.0,25$, and $50 \mu \mathrm{g} / \mathrm{mL})$ based on previous studies [18]. First, the media were prepared in $500 \mathrm{~mL}$ Erlenmeyer flasks containing $200 \mathrm{~mL}$ PDB and either valproic acid or 5-azacytidine as three replicates. Control PDB cultures were prepared without epigenetic modifiers. The broths were inoculated with freshly grown cultures of the endophytic fungus and incubated at $28^{\circ} \mathrm{C} \pm 2{ }^{\circ} \mathrm{C}$ on a rotary shaker at $110 \mathrm{rpm}$ for 30 days.

After incubation, the broths were filtered through Whatman No. 1 filter paper, and the collected supernatants were used for crude metabolite extraction. First, the supernatants $(200 \mathrm{~mL})$ were added into a separating funnel with an equal amount of ethyl acetate and 
shaken vigorously for $20 \mathrm{~min}$. The organic phase was collected into a $500 \mathrm{~mL}$ conical flask. The first step was repeated twice more. The crude extract in the organic phase was first evaporated in a rotatory evaporator (IKA, Königswinter, Germany) and finally dried in a fume hood. The crude compounds were weighed, dissolved in methanol, filtered through a $13 \mathrm{~mm}$ syringe filter with pore size $2 \mu \mathrm{m} 13 \mathrm{~mm}$ pore size syringe filter, and stored at $4{ }^{\circ} \mathrm{C}$.

\subsection{Bioactivities}

The crude extracts from the epigenetic modifier experiments and controls were used to perform antimicrobial activity assays. For this, sterile paper discs were impregnated with the crude extracts $(20 \mathrm{mg} / \mathrm{mL})$. The antibacterial test was carried out using a modified Kirby-Bauer method [48], where paper discs impregnated with ampicillin $(5 \mu \mathrm{g} / \mathrm{mL})$ and tetracycline $(5 \mu \mathrm{g} / \mathrm{mL})$ were used as positive controls. Four clinical human bacterial pathogens, namely P. aeruginosa, S. sonnei, S. pyogenes, and S. typhi (provided by the Department of Botany \& Microbiology, College of Science, King Saud University, Riyadh, Saudi Arabia), were inoculated into Mueller-Hinton agar plates. The paper discs with the crude extracts and positive controls were placed onto individual plates, which were then incubated overnight at $37^{\circ} \mathrm{C}$. After that time, the inhibition zones were measured.

The antifungal activity assay used was modified from the method of [49]. First, four plant pathogenic fungi-namely B. cineria, $R$. solani, $P$. recondite, and $P$. infestans (preserved at King Saud University) - were inoculated on PDA agar plates. Then, the paper discs impregnated with the crude extracts, PDA controls, and positive controls $(5 \mu \mathrm{g} / \mathrm{mL}$ gentamycin and $5 \mu \mathrm{g} / \mathrm{mL}$ fluconazole) were placed onto PDA plates, $4 \mathrm{~cm}$ away from the pathogenic cultures. The plates were incubated at $25^{\circ} \mathrm{C}$ for five days before the inhibition zones were measured.

The antioxidant potentials of the crude extracts were assessed using DPPH assays, which measured the free-radical-scavenging activity, as described by [50]. The samples $(2 \mathrm{~mL})$ such as the crude extract, positive control rosmarinic acid (Sigma-Aldrich Co, Saint Louis, MI, USA), and negative control glucose (Sigma-Aldrich Co, Saint Louis, MI, USA) were mixed with DPPH $(4 \mathrm{~mL})$ and incubated at $37^{\circ} \mathrm{C}$ in the dark for $30 \mathrm{~min}$ before the absorbance was measured at $517 \mathrm{~nm}$ using a spectrophotometer. Scavenging activity was calculated as the percentage of sample absorbance from that of the control (DPPH added in the crude extract of the medium with no epigenetic modifier). A lower percentage indicated higher scavenging activity.

\subsection{Chemical Analyses}

The crude extracts were analyzed with GC-MS/MS (fused silica $15 \mathrm{~m} \times 0.2 \mathrm{~mm}$ ID $\times 1 \mu \mathrm{m}$ of capillary column, Shimadzu GC-MS QP, Kyoto, Japan) and the sample injection volume was $1 \mu \mathrm{L}$. The settings were: initial temperature $30^{\circ} \mathrm{C}$ for $2 \mathrm{~min}$, gradual rise to $280{ }^{\circ} \mathrm{C}$ and maintenance for $9 \mathrm{~min}$, ionization voltage $70 \mathrm{eV}$, and mass spectral scan range $25-250 \mathrm{~m} / \mathrm{z}$. The GC-MS/MS data were interpreted with the NIST database performed with MMF (minimum match factor, NIST, Gaithersburg, MD, USA) 75 for all the components and also using the virtue of comparisons having more than 62,000 patterns.

$\mathrm{MRM} / \mathrm{MS}$ analysis was used to detect the antibiotic compound phenazine-1-carboxylic acid $\left(\mathrm{C}_{12} \mathrm{H}_{8} \mathrm{~N}\right)$ in the extracts. Agilent 6420 Triple Quad LC/MS system with C18-AR column, $3 \mu \mathrm{m}, 50 \times 4.6 \mathrm{~mm}$ (MAC-MOD Analytical Inc. Part No. EXL1190546U, MAC-MOD Analytical, Chadds Ford, PA, USA) was used with the mobile phase as acetonitrile-watertrifluoroacetic acid (90:10:0.04, $v / v / v)$ at flow rate $1.0 \mathrm{~mL} / \mathrm{min}$ and wavelength $248 \mathrm{~nm}$ and the sample injection volume was $1 \mu \mathrm{L}$.

\subsection{Statistical Analyses}

Two-way ANOVAs were carried out with epigenetic modifiers and concentrations as factors. If significant interactions were found, $t$-tests were carried out to analyze the effects of each concentration of epigenetic modifier in comparison to their respective positive controls. The tests were carried out separately for each of the eight pathogenic species. 
The data were log-transformed when necessary. Differences with $p<0.05$ were considered significant.

\section{Conclusions}

We can recommend that the endophytic fungus, $P$. heveicola can be utilized in biological plant protection and biomedicine. The addition of the epigenetic modifier, valproic acid, will greatly enhance the release of volatile bioactive metabolites. In contrast, 5-azacytidine is not an effective epigenetic modifier. In the tests, the antimicrobial efficiency depended largely on the concentration of valproic acid used, as it was shown that different compounds were released in different concentrations. Therefore, more complex study designs should be carried out to determine the optimal conditions for efficient production of these biomedical agents. For instance, mixing different epigenetic modifiers with different concentrations would be of interest. We can recommend that the endophyte of P. longum can be used to produce biologically active metabolites for biocontrol purposes.

Author Contributions: F.A.: analysis, writing, revising, A.A.; practical work and software, M.A.T.: investigation, N.A.-E.; resources and software; A.A.-S.; data curation, R.O.: Revising. All authors contributed to data analysis, drafting, or revising the manuscript. All authors have read and agreed to the published version of the manuscript.

Funding: This research was funded by the Deputyship for Research \& Innovation, "Ministry of Education" in Saudi Arabia through the project number IFK-SURG-1438-029.

Acknowledgments: The authors extend their appreciation to the Deputyship for Research \& Innovation, "Ministry of Education" in Saudi Arabia for funding this research work through the project number IFKSURG-1438-029.

Conflicts of Interest: All authors declare that they have no conflict of interest.

\section{References}

1. Yuan, H.; Ma, Q.; Ye, L.; Piao, G. The traditional medicine and modern medicine from natural products. Molecules 2016, 21, 559. [CrossRef] [PubMed]

2. Shukla, S.T.; Habbu, P.V.; Kulkarni, V.H.; Jagadish, K.S.; Pandey, A.R.; Sutariya, V.N. Endophytic microbes: A novel source for biologically/pharmacologically active secondary metabolites. Asian J. Pharmacol. Toxicol. 2014, 2, 1-6.

3. Korpi, A.; Järnberg, J.; Pasanen, A.-L. Microbial volatile organic compounds. Crit. Rev. Toxicol. 2009, 39, 139-193. [CrossRef] [PubMed]

4. Roy, S.; Banerjee, D. Volatile Organic Compounds from Endophytic Fungi. In Recent Advancement in White Biotechnology Through Fungi; Springer: Berlin/Heidelberg, Germany, 2019; pp. 149-175.

5. Khare, E.; Mishra, J.; Arora, N.K. Multifaceted interactions between endophytes and plant: Developments and prospects. Front. Microbiol. 2018, 9, 2732. [CrossRef]

6. Ahmed, F.; Ijaz, B.; Ahmad, Z.; Farooq, N.; Sarwar, M.B.; Husnain, T. Modification of miRNA Expression through plant extracts and compounds against Breast cancer: Mechanism and Translational Significance. Phytomedicine 2020, 68, 153168. [CrossRef]

7. Zutz, C.; Bandian, D.; Neumayer, B.; Speringer, F.; Gorfer, M.; Wagner, M.; Strauss, J.; Rychli, K. Fungi treated with small chemicals exhibit increased antimicrobial activity against facultative bacterial and yeast pathogens. BioMed. Res. Int. 2014, $2014,540292$. [CrossRef]

8. Blum, R. Stepping inside the realm of epigenetic modifiers. Biomol. Concepts 2015, 6, 119-136. [CrossRef]

9. Zutz, C.; Gacek, A.; Sulyok, M.; Wagner, M.; Strauss, J.; Rychli, K. Small chemical chromatin effectors alter secondary metabolite production in Aspergillus clavatus. Toxins 2013, 5, 1723-1741. [CrossRef]

10. Chen, H.-J.; Awakawa, T.; Sun, J.-Y.; Wakimoto, T.; Abe, I. Epigenetic modifier-induced biosynthesis of novel fusaric acid derivatives in endophytic fungi from Datura stramonium L. Natural Products Bioprospecting 2013, 3, 20-23. [CrossRef]

11. Al Akeel, R. Role of epigenetic reprogramming of host genes in bacterial pathogenesis. Saudi J. Biol. Sci. 2013, 20, 305-309. [CrossRef]

12. Pfannenstiel, B.T.; Keller, N.P. On top of biosynthetic gene clusters: How epigenetic machinery influences secondary metabolism in fungi. Biotechnol. Adv. 2019, 37, 107345. [CrossRef] [PubMed]

13. Lee, M.-J.; Tsai, Y.-J.; Lin, M.-Y.; You, H.-L.; Kalyanam, N.; Ho, C.-T.; Pan, M.-H. Calebin-A induced death of malignant peripheral nerve sheath tumor cells by activation of histone acetyltransferase. Phytomedicine 2019, 57, 377-384. [CrossRef] [PubMed]

14. Beau, J.; Mahid, N.; Burda, W.N.; Harrington, L.; Shaw, L.N.; Mutka, T.; Kyle, D.E.; Barisic, B.; Van Olphen, A.; Baker, B.J. Epigenetic tailoring for the production of anti-infective cytosporones from the marine fungus Leucostoma persoonii. Mar. Drugs 2012, 10, 762-774. [CrossRef] [PubMed] 
15. Chen, M.; Zhang, W.; Shao, C.-L.; Chi, Z.-M.; Wang, C.-Y. DNA methyltransferase inhibitor induced fungal biosynthetic products: Diethylene glycol phthalate ester oligomers from the marine-derived fungus Cochliobolus lunatus. Mar. Biotechnol. 2016, 18, 409-417. [CrossRef]

16. Sun, J.; Awakawa, T.; Noguchi, H.; Abe, I. Induced production of mycotoxins in an endophytic fungus from the medicinal plant Datura stramonium L. Bioorganic Med. Chem. Lett. 2012, 22, 6397-6400. [CrossRef]

17. Sharma, V.K.; Kumar, J.; Singh, D.K.; Mishra, A.; Verma, S.K.; Gond, S.K.; Kumar, A.; Singh, N.; Kharwar, R.N. Induction of Cryptic and Bioactive Metabolites through Natural Dietary Components in an Endophytic Fungus Colletotrichum gloeosporioides (Penz.) Sacc. Front. Microbiol. 2017, 8, 1126. [CrossRef]

18. Chung, Y.-M.; El-Shazly, M.; Chuang, D.-W.; Hwang, T.-L.; Asai, T.; Oshima, Y.; Ashour, M.L.; Wu, Y.-C.; Chang, F.-R. Suberoylanilide hydroxamic acid, a histone deacetylase inhibitor, induces the production of anti-inflammatory cyclodepsipeptides from Beauveria felina. J. Natural Products 2013, 76, 1260-1266. [CrossRef]

19. Chung, Y.-M.; Wei, C.-K.; Chuang, D.-W.; El-Shazly, M.; Hsieh, C.-T.; Asai, T.; Oshima, Y.; Hsieh, T.-J.; Hwang, T.-L.; Wu, Y.-C.; et al. An epigenetic modifier enhances the production of anti-diabetic and anti-inflammatory sesquiterpenoids from Aspergillus sydowii. Bioorganic Med. Chem. 2013, 21, 3866-3872. [CrossRef]

20. Yadav, V.; Krishnan, A.; Vohora, D. A systematic review on Piper longum L.: Bridging traditional knowledge and pharmacological evidence for future translational research. J. Ethnopharmacol. 2020, 247, 112255. [CrossRef]

21. Salehi, B.; Zakaria, Z.A.; Gyawali, R.; Ibrahim, S.A.; Rajkovic, J.; Shinwari, Z.K.; Khan, T.; Sharifi-Rad, J.; Ozleyen, A.; Turkdonmez, E.; et al. Piper species: A comprehensive review on their phytochemistry, biological activities and applications. Molecules 2019, 24, 1364. [CrossRef]

22. Pierson, L.S.; Pierson, E.A. Metabolism and function of phenazines in bacteria: Impacts on the behavior of bacteria in the environment and biotechnological processes. Appl. Microbiol. Biotechnol. 2010, 86, 1659-1670. [CrossRef] [PubMed]

23. Price-Whelan, A.; Dietrich, L.E.P.; Newman, D.K. Rethinking'secondary'metabolism: Physiological roles for phenazine antibiotics. Nature Chem. Biol. 2006, 2, 71-78. [CrossRef] [PubMed]

24. Remali, J.; Sarmin, N.M.; Ng, C.L.; Tiong, J.J.L.; Aizat, W.M.; Keong, L.K.; Zin, N.M. Genomic characterization of a new endophytic Streptomyces kebangsaanensis identifies biosynthetic pathway gene clusters for novel phenazine antibiotic production. PeerJ 2017, 5, e3738. [CrossRef] [PubMed]

25. Thanabalasingam, D.; Kumar, N.S.; Jayasinghe, L.; Fujimoto, Y. Endophytic Fungus Nigrospora oryzae from a Medicinal plant Coccinia grandis, a High Yielding New Source of Phenazine-l-carboxamide. Natural Product Commun. 2015, 10, 1934578X1501001008. [CrossRef]

26. Sethuraman, K.N.; Jones, J.; Dyer, K.S. Anesthetic-Agent Mass Casualty Incident. In Ciottone's Disaster Medicine; Elsevier: Amsterdam, The Netherlands, 2016; pp. 692-695.

27. Othman, A.A.; Kihel, M.; Amara, S. 1, 3, 4-Oxadiazole, 1, 3, 4-thiadiazole and 1, 2, 4-triazole derivatives as potential antibacterial agents. Arabian J. Chem. 2019, 12, 1660-1675. [CrossRef]

28. Ser, H.-L.; Palanisamy, U.D.; Yin, W.-F.; Abd Malek, S.N.; Chan, K.-G.; Goh, B.-H.; Lee, L.-H. Presence of antioxidative agent, Pyrrolo [1, 2-a] pyrazine-1, 4-dione, hexahydro-in newly isolated Streptomyces mangrovisoli sp. nov. Front. Microbiol. 2015, 6, 854. [CrossRef]

29. George, A.B. Fenaroli's Handbook of Flavor Ingredients; CRC Press: Boca Raton, FL, USA, 2009.

30. Yu, P.H.; Deng, Y.L. Endogenous formaldehyde as a potential factor of vulnerability of atherosclerosis: Involvement of semicarbazide-sensitive amine oxidase-mediated methylamine turnover. Atherosclerosis 1998, 140, 357-363. [CrossRef]

31. Qureshi, A.; Pradhan, A. Short Review on Thiazole Derivative. J. Drug Deliv. Ther. 2019, 9, 842-847.

32. Schiestl, F.P.; Roubik, D.W. Odor compound detection in male euglossine bees. J. Chem. Ecol. 2003, 29, 253-257. [CrossRef]

33. Wang, S.; Yao, Z.; Hou, Y.; Wang, D.; Zhang, H.; Ma, J.; Zhang, L.; Liu, S. Prevalence of Enterobius vermicularis among preschool children in 2003 and 2013 in Xinxiang city, Henan province, Central China. Parasite 2016, 23, 30. [CrossRef]

34. Machida, S.; Mukai, S.; Kono, R.; Funato, M.; Saito, H.; Uchiyama, T. Synthesis and Comparative Structure-Activity Study of Carbohydrate-Based Phenolic Compounds as \$ \$\$-Glucosidase Inhibitors and Antioxidants. Molecules 2019, 24, 4340. [CrossRef] [PubMed]

35. Lopes, A.A.; da Silva, D.B.; Lopes, N.P.; Pupo, M.T. Epigenetic modulation changed the secondary metabolite profile in the endophyte Nigrospora sphaerica SS67. Planta Medica 2012, 78, PL38. [CrossRef]

36. Magotra, A.; Kumar, M.; Kushwaha, M.; Awasthi, P.; Raina, C.; Gupta, A.P.; Shah, B.A.; Gandhi, S.G.; Chaubey, A. Epigenetic modifier induced enhancement of fumiquinazoline $C$ production in Aspergillus fumigatus (GA-L7): An endophytic fungus from Grewia asiatica L. AMB Express 2017, 7, 1-10. [CrossRef] [PubMed]

37. de Felicio, R.; Pavão, G.B.; de Oliveira, A.L.L.; Erbert, C.; Conti, R.; Pupo, M.T.; Furtado, N.A.J.C.; Ferreira, E.G.; Costa-Lotufo, L.V.; Young, M.C.M.; et al. Antibacterial, antifungal and cytotoxic activities exhibited by endophytic fungi from the Brazilian marine red alga Bostrychia tenella (Ceramiales). Rev. Bras. Farmacogn. 2015, 25, 641-650. [CrossRef]

38. Verma, V.C.; Lobkovsky, E.; Gange, A.C.; Singh, S.K.; Prakash, S. Piperine production by endophytic fungus Periconia sp. isolated from Piper longum L. J. Antibiot. 2011, 64, 427-431. [CrossRef] [PubMed]

39. Toghueo, R.M.K. Anti-leishmanial and Anti-inflammatory Agents from Endophytes: A Review. Natural Products Bioprospecting 2019, 9, 1-18. [CrossRef] 
40. Chithra, S.; Jasim, B.; Sachidanandan, P.; Jyothis, M.; Radhakrishnan, E.K. Piperine production by endophytic fungus Colletotrichum gloeosporioides isolated from Piper nigrum. Phytomedicine 2014, 21, 534-540. [CrossRef]

41. Silva, G.H.; Teles, H.L.; Trevisan, H.C.; Bolzani, V. da S.; Young, M.; Pfenning, L.H.; Eberlin, M.N.; Haddad, R.; Costa-Neto, C.M.; Araújo, Â.R. New bioactive metabolites produced by Phomopsis cassiae, an endophytic fungus in Cassia spectabilis. J. Braz. Chem. Soc. 2005, 16, 1463-1466. [CrossRef]

42. Rajamani, T.; Suryanarayanan, T.S.; Murali, T.S.; Thirunavukkarasu, N. Distribution and diversity of foliar endophytic fungi in the mangroves of Andaman Islands, India. Fungal Ecol. 2018, 36, 109-116. [CrossRef]

43. Gong, J.L.; Lu, Y.; Wu, W.H.; He, C.P.; Liang, Y.Q.; Huang, X.; Zheng, J.L.; Xi, J.G.; Tang, S.B.; Yi, K.X. First Report of Phomopsis heveicola (Anamorph of Diaporthe tulliensis) Causing Leaf Blight of Coffee (Coffea arabica) in China. Plant Disease 2019, 104, 570. [CrossRef]

44. Araújo, W.L.; Maccheroni Jr, W.; Aguilar-Vildoso, C.I.; Barroso, P.A.V.; Saridakis, H.O.; Azevedo, J.L. Variability and interactions between endophytic bacteria and fungi isolated from leaf tissues of citrus rootstocks. Can. J. Microbiol. 2001, 47, 229-236. [CrossRef] [PubMed]

45. Summerbell, R.C.; Gueidan, C.; Schroers, H.J.; De Hoog, G.S.; Starink, M.; Rosete, Y.A.; Guarro, J.; Scott, J.A. Acremonium phylogenetic overview and revision of Gliomastix, Sarocladium, and Trichothecium. Studies Mycol. 2011, 68, 139-162. [CrossRef] [PubMed]

46. Bozzola, J.J.; Russell, L.D. Electron Microscopy: Principles and Techniques for Biologists; Jones \& Bartlett Learning: Burlington, MA, USA, 1999.

47. Huerta-Cepas, J.; Szklarczyk, D.; Forslund, K.; Cook, H.; Heller, D.; Walter, M.C.; Rattei, T.; Mende, D.R.; Sunagawa, S.; Kuhn, M.; et al. eggNOG 4.5: A hierarchical orthology framework with improved functional annotations for eukaryotic, prokaryotic and viral sequences. Nucleic Acids Res. 2016, 44, D286-D293. [CrossRef] [PubMed]

48. Cheesbrough, M. District Laboratory Practice in Tropical Countries; Cambridge University Press: Cambridge, UK, 2006.

49. Strobel, G.A.; Dirkse, E.; Sears, J.; Markworth, C. Volatile antimicrobials from Muscodor albus, a novel endophytic fungus. Microbiology 2001, 147, 2943-2950. [CrossRef]

50. Benmerache, A.; Benteldjoune, M.; Alabdul Magid, A.; Abedini, A.; Berrehal, D.; Kabouche, A.; Gangloff, S.C.; VoutquenneNazabadioko, L.; Kabouche, Z. Chemical composition, antioxidant and antibacterial activities of Tamarix balansae J. Gay aerial parts. Natural Product Res. 2017, 31, 2828-2835. [CrossRef] [PubMed] 